\title{
Fruit and Nut Tree Pruning Guidelines for Arborists
}

CHUCK INGELS, UC Cooperative Extension Farm and Horticulture Advisor, Sacramento County; and PAM GEISEL, former Director, UC Statewide Master Gardener

Program, and former

UC Cooperative Extension Horticulture Advisor, Fresno County, and County Director, Glenn County
Irborists are well versed in the use of central (single) leader training for most ornamental
trees. Central leader training ensures strong structure, increases longevity, and reduces limb failures. Trees trained to a single leader typically have a central axis from which lateral branches originate. This serves to prevent the formation of codominant branches, which lack a strong attachment union. It also helps to improve vertical branch separation. The main objective of central leader pruning (also called structural pruning) is to keep the lateral branches less than 50 percent of the diameter of the leader and retain wide-angled branches. This ensures a strong branch union to bear the weight of the branch. Sunlight penetration to lower, inner branches is not essential for ornamental trees, and the majority of the foliage and flowers grow primarily on the outside of the canopy.

Fruit trees differ from landscape trees in that they are best kept relatively small to facilitate routine pruning, fruit thinning, managing pests, and harvesting fruit from the ground or a ladder. Fruit trees that are allowed to grow above a manageable height produce excessive fruit, leading to branch breakage, smaller-size fruit, and, in some cases, pest problems (fig. 1). Most fruit trees are trained to the open center system and are topped annually to reduce limb breakage. However,

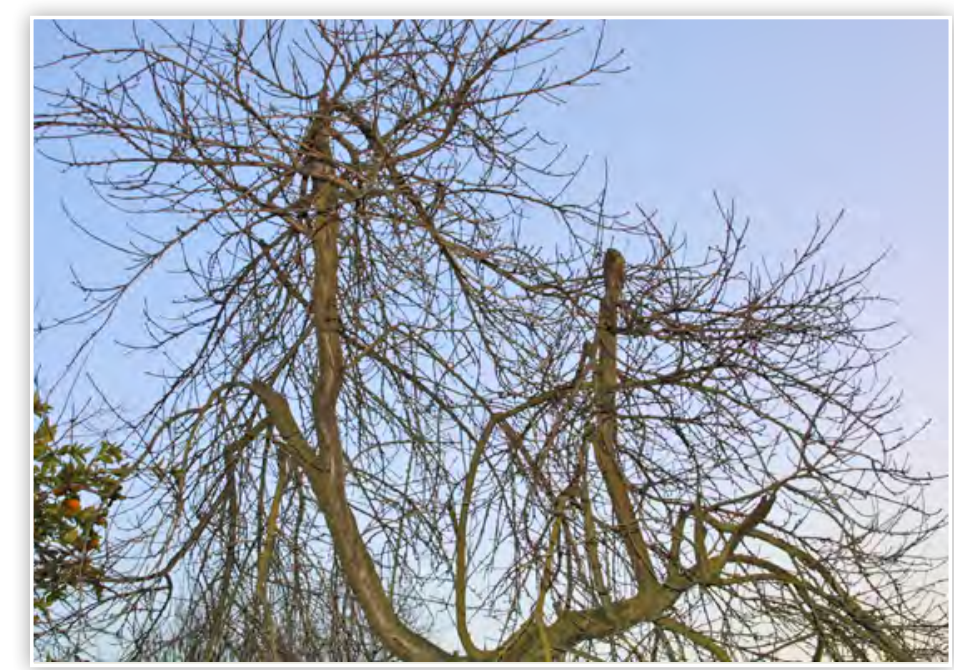

Figure 1. Overgrown plum tree with poor structure and branches broken from the weight of the fruit. Excessive growth high in the tree shades lower fruiting branches, rendering them fruitless and thereby shifting fruit production beyond reach. 
Figure 2. Genetic dwarf peach with open center. Shoots on genetic dwarf trees have short internode distances, so flowers and

leaves are dense, requiring thinning of branches for sunlight penetration and substantial fruit thinning to size the fruit and prevent branch breakage.

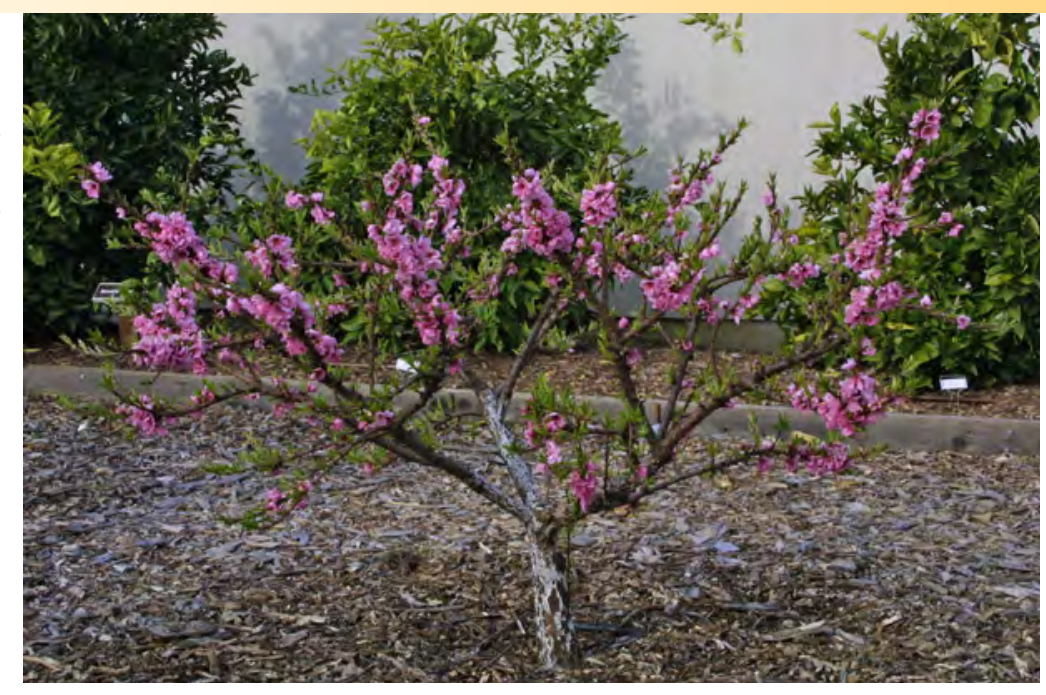

some fruit trees lend themselves to central leader training, so these considerations are less important. The major problem with those that do grow very tall, however, is that the fruit are borne higher in the tree and the lower branches become shaded. This results in the decline of these branches and ultimately renders them fruitless.

Unlike fruits, nuts are knocked, shaken, or allowed to fall. They are not usually picked by hand, so tree height is less important. Some size control is necessary for preventing branch failures and maximizing nut production, because large trees are more difficult to knock. Pruning of nut trees generally consists of thinning or cutting back selected branches to suitable lateral branches. Walnut and pistachio trees should be trained to a modified central leader to maximize fruit production and maintain a branch structure that can support the nut crop (see the section "Modified Central Leader").

\section{Semidwarf and Genetic Dwarf Trees}

The best strategy for keeping trees relatively small is to use a dwarfing rootstock when available. Trees on dwarfing rootstocks are smaller than those on standard or seedling rootstocks. However, semidwarf rootstocks differ in their ability to cause dwarfing, and many semidwarf trees sold in retail nurseries are only slightly dwarfing. For example, apple rootstocks can range from about 80 percent of the size of a standard tree (e.g., M111, one of the most common apple rootstocks sold) to about 60 percent (e.g.,
M7a) to about 30 percent (e.g., M9). Therefore, some semidwarfs are still, practically speaking, full-size trees. Other fruit species do not have this range of dwarfing rootstocks available, and most are only slightly dwarfing. For the stone fruits, such as peaches and nectarines, the dwarfing rootstock most commonly available is Citation, which produces a tree that is somewhat smaller. Citrus can be dwarfed to approximately 50 percent by growing trees on the 'Flying Dragon' trifoliate orange rootstock. However, availability of trees grafted to 'Flying Dragon' is limited due to the very slow growth of grafted trees.

Genetic dwarf trees are very easy to manage and are aesthetically pleasing in the landscape (fig. 2). They naturally produce short internodes and are usually planted on standard rootstocks. A limited number of genetic dwarf varieties are available for almond, apple, apricot, nectarine, and peach.

\section{Training Fruit and Nut Trees for Production and Landscape Aesthetics}

\section{Planting and Early Tree Care}

Deciduous fruit and nut trees are ideally planted bare root, but containerized trees can also be used. All bare-root trees intended solely for fruit or almond production should be headed 18 to 24 inches above the ground at planting to force low branching; walnuts and pecans should be headed higher. (For converting U.S. customary units to metric units, see the table at the end of this publication.) If this were not done, the first laterals would typically form around 5 to 6 feet above the ground, growth would be weak, and much of the fruit would be out of reach from the ground. It is important to develop a new leader in headed trees if the central leader method is to be maintained. Select one of the shoots that grow near the heading cut, and tie it to a stake in an upright position if it is not growing upright naturally. Additional pruning may be needed to eliminate branch crowding or prevent codominant trunks from forming. Higher branching may be desirable for fruit trees in some urban settings to allow for maintenance of vegetation under and around the tree. In areas where deer are a problem, lower branching 
may not be practical without proper protection. Containerized fruit trees are often planted in spring or summer, so they cannot be headed without removing all the foliage. Either leave the tree as it was headed in the nursery, or make the lower heading cut in the next dormant season. In hot regions where afternoon sun hits the trunk, apply a white interior latex paint diluted 50-50 with water to the trunk to prevent sunburn injury.

\section{Tree Training Considerations}

Each fruit and nut species has a preferred training method based on the species' growth habits and fruiting characteristics. Ideally, most of the fruit should be produced low in the tree to facilitate fruit thinning, pest management, and harvest. Because fruit is produced on spurs or 1-year-old branches that require sunlight for flower development, direct sun must penetrate into the lower portions of the canopy for fruit production low in the tree. Nearly all fruits and nuts are borne mainly on spurs, but peach and nectarine fruit are borne only on 1-year-old shoots that grew the previous summer.

Most stone fruits and almonds are best trained to the "open center" or "open vase" method, where the center of the tree is routinely kept free of vigorous shoots. In this manner, lower fruiting branches receive sufficient light through the tree's center. Apples and pears can also be trained to the open center system but are better adapted to central leader training, where lateral branches are trained outward from a vertical leader allowing sunlight to penetrate from the sides. Persimmons are also well adapted to central leader training.

For apples and pears it may be prudent to develop two or three leaders in case fire blight kills one of the leaders; lateral branches are directed to the outside of the tree. Apples and pears can also be espalier trained. This method involves pruning the tree to form a narrow, flat plane on a trellis or against a wall or fence. Permanent, horizontal branches that resemble cordons on grapevines are selected to produce the fruiting spurs.

Walnuts, pistachios, and persimmons can also be initially trained with a central leader, but then trees are allowed to develop a natural rounded crown; this method is referred to as "modified central leader" training. Fig trees can also be trained using this method or using open center training, and they can be kept fairly short or allowed to grow tall, or they can even be espalier trained. Modified central leader training can be used for pomegranates, but their rangy growth and constant root suckering make them better adapted to a system that allows them to grow into a large multitrunked bush. Pruning them typically involves heading back and thinning vigorous upright branches and removing old trunks or scaffold (main) branches to rejuvenate trees.

Citrus trees can be allowed to grow with little training except to eliminate scaffold branches with narrow crotch angles. Manage water sprouts (excessively vigorous upright shoots) by heading, shortening to a lower lateral, or, in some cases, completely removing. Save water sprouts that bend over, ultimately contributing to the typical mounding citrus canopy. Remove all rootstock suckers; they often grow up the center and are difficult to see. Painting the trunk white not only helps to prevent sunburn but will also make rootstock suckers easier to spot. Over time, the shaded inner fruiting branches of citrus trees die, and fruit production moves to the top and sides. This characteristic is considered acceptable for citrus. Citrus trees can also be hedged, and they are very adaptable to espalier training.

Nearly all species can be trained as fruit bushes, using a method in which trees are trained in the first and second year by heading shoots when they reach about 2 feet in length. The resulting new shoots are headed again, and this is followed each time by some thinning of shoots as well. Once the desired tree height is achieved (typically 5 to 7 feet), pruning consists of removing shoots above the desired height and thinning remaining shoots and branches about twice a year. Nearly all pruning on fruit bushes should be done in the growing season to reduce their vigor, but touch-up pruning is useful in winter, when branch structure is more visible

Apricots and cherries should be pruned only in late summer, when dry weather is predicted for an extended period. These species are susceptible to branch canker diseases, caused mainly by Eutypa and Botryosphaeria fungi, which infect branch injuries (such as pruning wounds) made before or during wet weather or periods of 


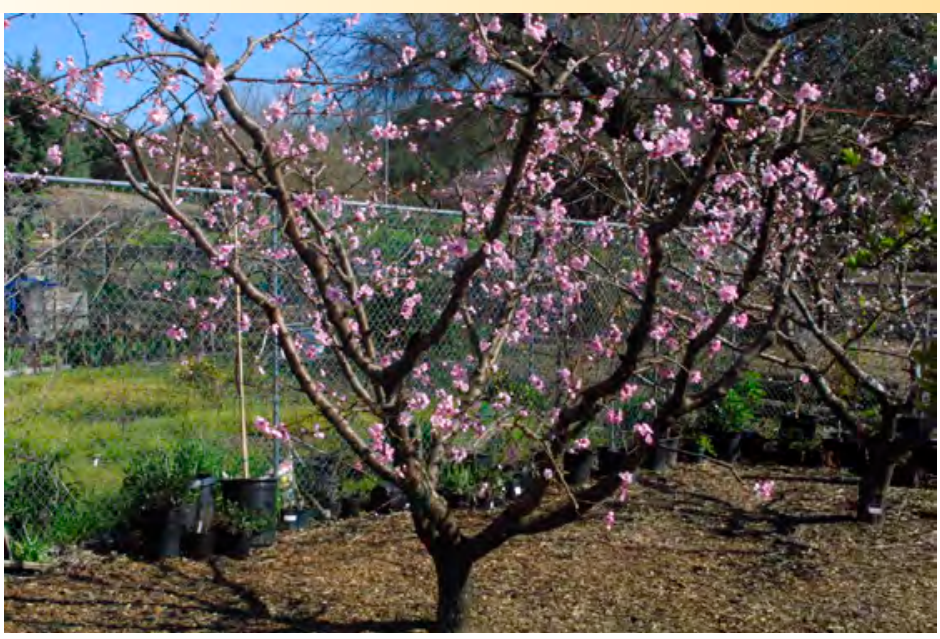

Figure 3. Open center peach tree, with flowering both high and low in the tree. The center must be kept open from the start of training and kept open each year, preferably with summer pruning to remove vigorous upright shoots in the center.

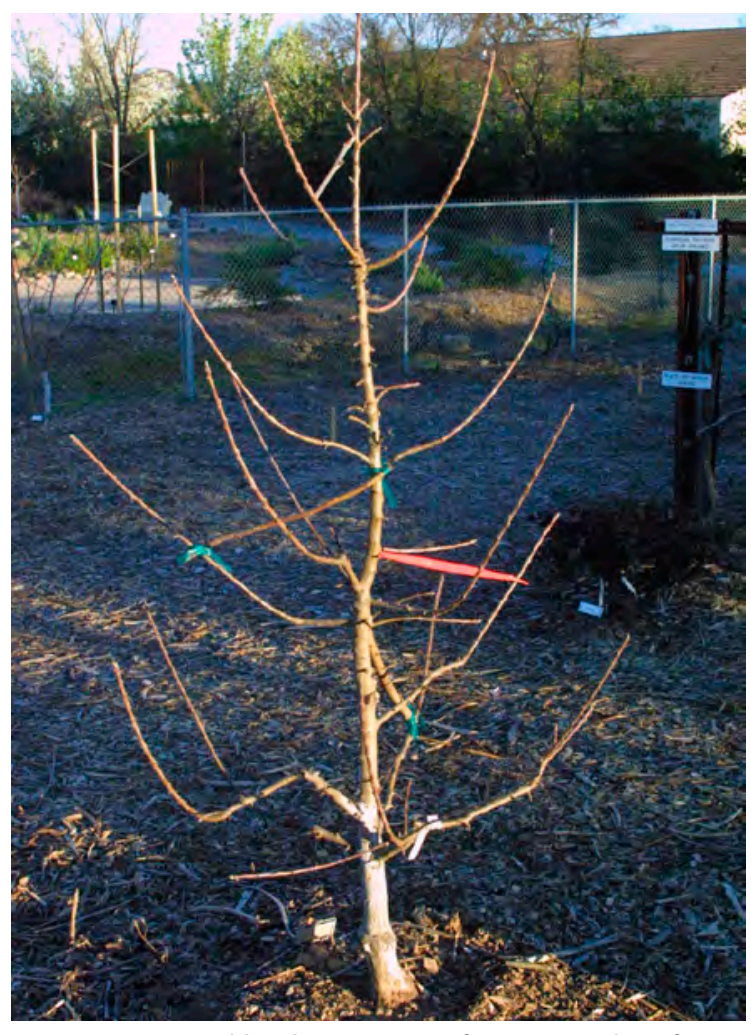

Figure 4. Central leader training of a genetic dwarf apple, showing spreading of lateral branches that grew too upright and would have competed with the leader.

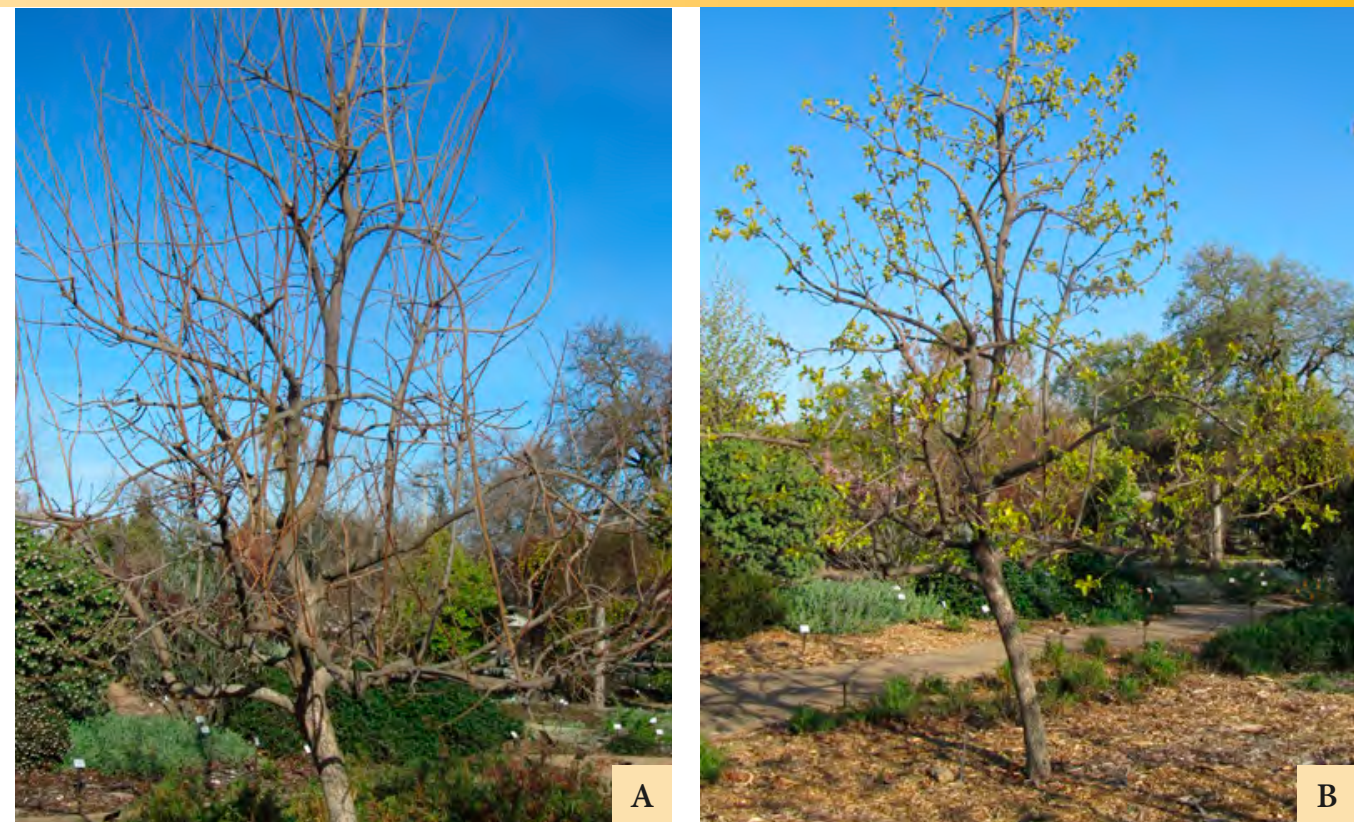

Figure 5. Central leader persimmon before $(A)$ and after $(B)$ pruning, from which vigorous upright shoots were removed to maintain the dominance of the leader and lateral branches were thinned to prevent overcropping and limb breakage. The tree is 12 feet tall.

very high humidity. However, most other fruit and nut trees can be pruned any time enough leaves have fallen to make the tree structure visible.

\section{Open Center or Open Vase}

After planting and heading bare-root stone fruit trees, two options are possible for the resulting shoots. Either they are allowed to grow through the summer, or training can begin during the first growing season by selecting three or four well-placed shoots (future scaffold branches) when they are 1 to 3 feet long and heading back all other shoots to 4 to 6 inches. By winter, the primary scaffold branches are selected and headed, and all other upright branches are removed. Continue to develop the tree to a vase shape over the next 2 years. Ideally, each primary scaffold should branch into two secondary branches, which, in turn, branch into two tertiary branches. Prune out vigorous upright shoots in the tree's center in winter, and maintain the open center by removing vigorous upright shoots once during summer. In winter, thin fruiting branches to reduce fruit load and minimize the need for fruit thinning. Head the trees back to about the same height every year, preferably to a height that can be reached using only a short ladder (fig. 3). With almond trees, scaffold branches are selected as with stone fruit trees. After that, however, the opening in the center of the tree can be somewhat narrower than stone fruit trees. Annual pruning involves thinning branches to avoid overcrowding.

\section{Central Leader}

Apples, pears, persimmons, and pecan trees are best trained to develop a central leader similar to those in many shade and ornamental trees (figs. 4 and 5). Lateral branches grow outward from the leader, either in tiers of approximately four branches each or spaced fairly uniformly up and around the trunk. Rather than simply allowing 
the trunk to continue growing naturally after planting, the trunk is headed at about 18 to 24 inches above the ground, and the most vigorous and upright shoot that develops is selected to become the new leader. This practice is done to force the first tier of four lateral branches below the heading cut. When the new leader has grown about 2.5 feet, it is then headed back about 6 inches. A new central, upright shoot is selected to continue the leader, and the lateral branches that develop will create the second tier. This pattern is repeated until the desired tree height is reached. Alternatively, lateral branches can simply be vertically and radially separated up the trunk. To prevent lateral branches from competing with the leader, bend branches outward to 45 to 60 degrees from vertical, if needed, using branch spreaders or string tie-downs. Each branch must be offset somewhat from the branch immediately below it to prevent shading. Lower branches are allowed to grow longer than those higher in the tree to encourage sunlight penetration and keep lower fruitwood alive. Tree height is usually limited to about 8 feet for dwarf trees and 10 to 12 feet for semidwarf or standard trees.
Figure 6. Walnut trees with modified central leader training. The leader can remain short or long, as in this photo, but lateral scaffold branches usually become codominant at some point.

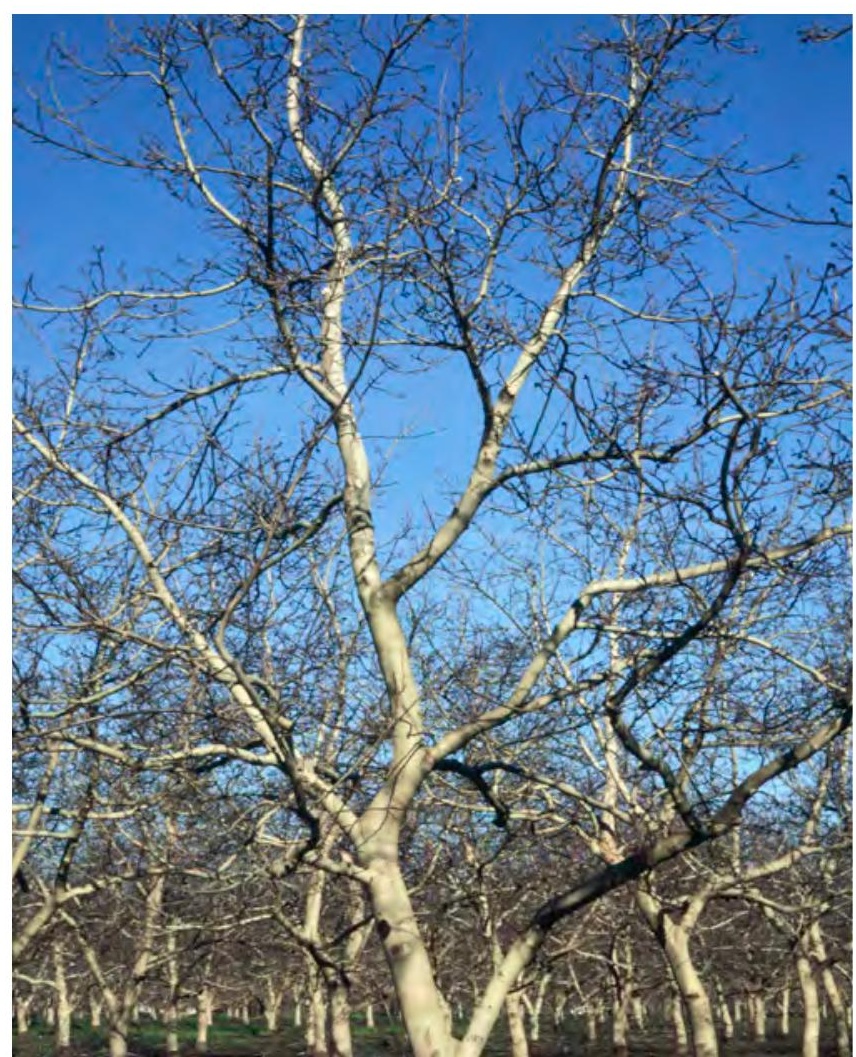

Persimmon flowers grow on new shoots that originate toward the ends of 1-year-old branches; thus, early training should include heading these branches in winter to prevent structural branches from bending excessively due to the fruit weight.

\section{Modified Central Leader}

This method is an option for walnuts (fig. 6), persimmons, pistachios, and pomegranates. After the central leader is formed and five to seven lateral branches are formed radially around the trunk with at least 6 to 12 inches of vertical spacing from each other, the leader is headed back or simply allowed to develop a few competing (codominant) leaders. However, the lower canopy should still remain wider than the upper canopy to allow light to reach the lower branches. Annual pruning of walnuts involves strategically thinning branches to allow sunlight through the canopy but not creating openings large enough to result in sunburn damage to large, newly exposed limbs.

\section{Fruit Bushes}

Fruit bushes have become very popular due to their ease of management and the accessibility of their fruit (fig. 7). Fruit bush trees

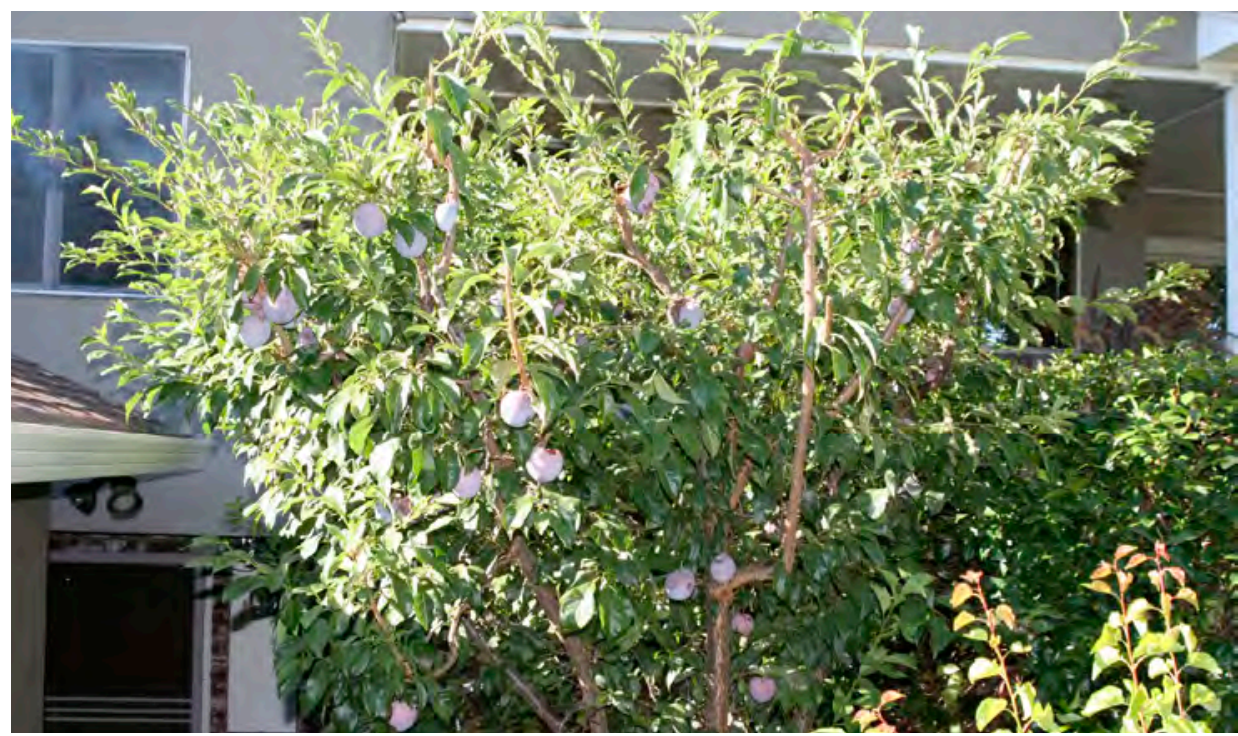

Figure 7. Pluot fruit bush in a raised planter. The tree is maintained at 6 to 7 feet tall and wide, using two summer prunings to remove vigorous upright shoots and thin branches. Such pruning maintains tree height and allows light to reach the tree's interior. 


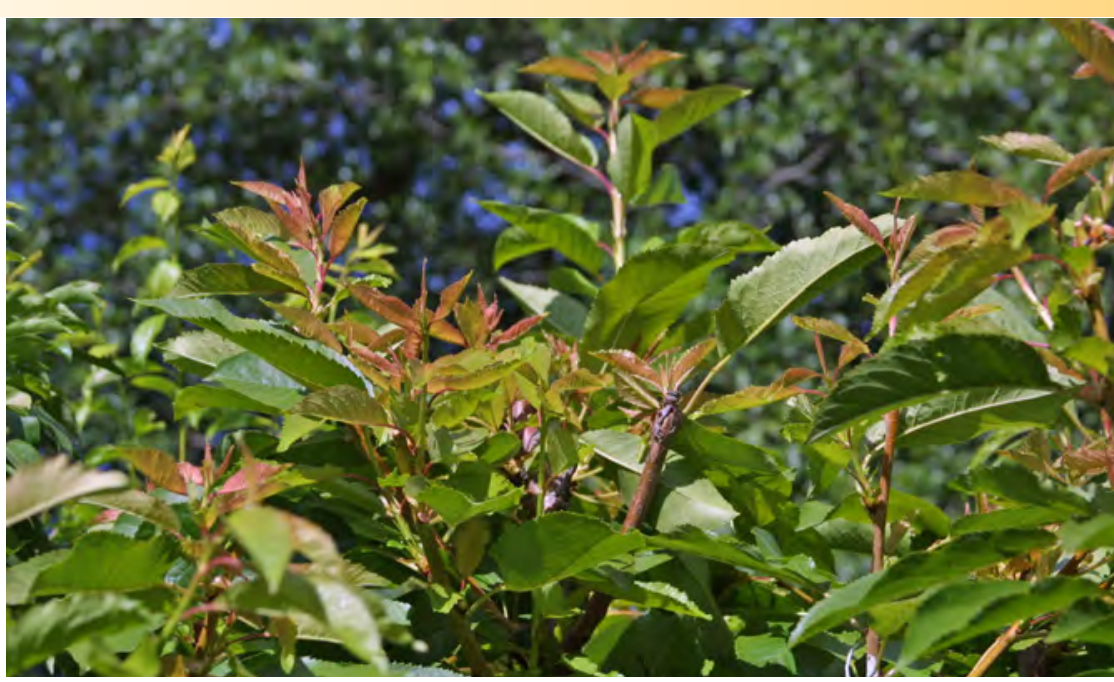

Figure 8. Vigorous regrowth after the first summer pruning of a cherry bush. New shoots can quickly shade lower fruiting branches, so shoots or branches near the top (or both) should be thinned.

are developed on standard or dwarfing rootstock and are kept small by heading during the growing season. To create a fruit bush, after planting and heading the tree, shoot length is reduced by half when shoots reach about 2 to 3 feet. When the subsequent shoots reach the same length, they too are similarly shortened. Usually two such prunings are sufficient in the first year (in about May and July), but more vigorous trees may require such pruning three times. Since heading cuts cause several new shoots to grow, some should be thinned to prevent crowding. The process is continued in the second year, or until the permanent tree height is reachedusually 5 to 7 feet. Pruning mature trees consists of cutting off new shoots above the established height two to three times during each growing season and thinning branches and shoots to allow sunlight penetration (fig. 8). It may be beneficial to keep the center of the tree open to increase light in the lower canopy.

\section{Espalier}

Training trees on a sturdy trellis can provide a fruiting wall in a narrow space, either freestanding (preferable) or against a fence or house (fig. 9). Apples, pears, Asian pears, and citrus are especially well adapted to espalier training. Many ways exist to train the branches, but typically three to four horizontal wires are spaced about $1 \frac{1}{2}$ to 2 feet apart vertically, and the lateral shoots are tied

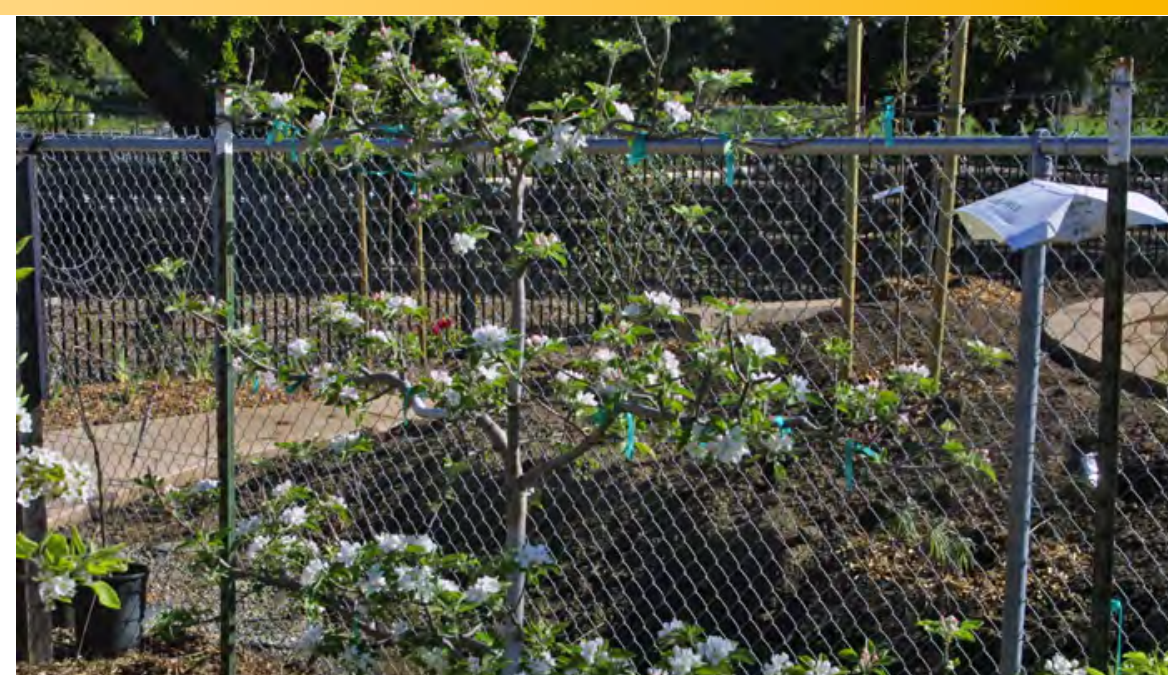

Figure 9. Young espaliered apple, with main branches going in opposite directions from the trunk on each of three wires.

(trained) along the wire running in either direction. Alternatively, lateral shoots could initially be directed upward and outward to create a fan shape, or upright branches could be created from main lateral limbs. Unwanted vigorous upright shoots should be cut back during the growing season to reduce shading and to encourage spurs along lateral branches. Lateral growth from the branches should be kept short to prevent shading of lower branches. If shoot growth is excessive, provide more space by extending the trellis outward or upward. Do not allow branches to grow through small holes in a fence or they will become girdled or break the fence.

\section{Pruning Overgrown Trees}

\section{Factors to Consider}

Arborists are often asked to prune large, overgrown fruit trees. After first determining the client's goals for a tree, the arborist can then develop a pruning approach or, preferably, a long-term maintenance plan. The health of the tree should be evaluated because large, older trees have often been neglected or poorly pruned. Some may be in decline and there may be extensive branch dieback, bleeding or gumming, wood rot, root rot, or branch cankers. Sunburned or diseased branches may also secondarily be infested with shot hole borer or Pacific flathead borer. The presence 
of such conditions and injuries could, depending on severity, make restorative pruning pointless. Also, determine if structural limbs are present low enough to warrant lowering the tree height to an acceptable level for picking fruit. Evaluate the amount of shade cast by nearby ornamental trees, which may have grown tall and now excessively shade the fruit tree, especially if the height is to be reduced.

\section{Scenarios}

Below are scenarios to discuss with the client regarding such trees:

- In some cases, the client has little interest in the fruit and simply wants the tree height reduced. This may not be a wise strategy, since unmanaged fruit loads will create a mess and may attract pests or rodents. Nonetheless, the crowns of such trees can be reduced moderately by heading smaller branches or cutting branches larger than about 4 inches back to lower laterals. This can stimulate rapid growth that requires follow-up pruning and creates large wounds that may become infected with wood decay pathogens. It should be pointed out that replacing the tree with an ornamental tree or large shrub that would grow to fill the space may be a better choice, since branch breakage and tree maintenance would be reduced.

- Some fruit and nut trees are fine when left as large trees, and often such trees enhance the aesthetics of the landscape, assuming that no hardscape is present on which fruit can create a mess. Branches bending downward can supply some fruit for eating, and birds eat much of the higher fruit. Pruning for such trees should involve removing dead branches and improving branch architecture to minimize branch and trunk failure. Strong, properly spaced scaffold branch structure should be selected and maintained by cutting to lower laterals of sufficient size or thinning out excessive branches. Interfering, overextended, defective, weak, and poorly attached branches should be removed or reduced. Pruning should be done to manage branch length, fruit load, directional orientation, and aspect ratios (diameter of the branch relative to the main stem or parent branch). In most cases, branch aspect should be maintained at less than 50 percent. Pruning can alter aspect ratio over time by suppressing growth in the pruned branch and invigorating growth

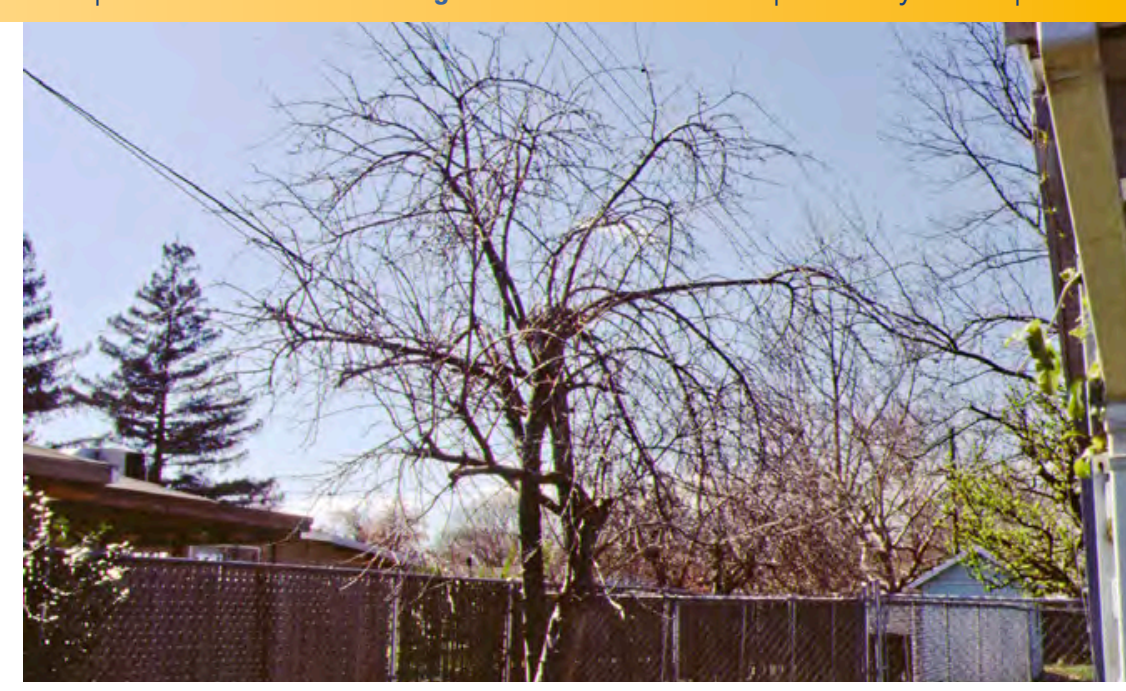

Figure 10. This overgrown apple tree was previously topped high in the tree, which simply promoted new branches originating just below the cut. The tree quickly grew back to where it was before, and even if the desired goal was to reduce the tree height, no satisfactory low branches grew to develop a new framework.

in the unpruned stem. Thinning is also useful to reduce branch weight, open avenues for sunlight penetration into the lower canopy, and reduce the fruit load. Spurs and fruiting branches should be thinned or rejuvenated by cutting back to younger wood, which will produce larger fruit. Avoid removing large, older limbs, because of the likelihood of introducing wood decay organisms, unless the tree is overgrown and must be structurally reduced.

- If maximum fruit production is desired and the client wants to learn how to manage a smaller tree, a strategy for bringing down tree height and managing the canopy for light penetration and pruning-both dormant and summer pruning-should be developed.

\section{Lowering Tree Height}

The standard method has been to reduce the tree height by thirds over a period of 3 years. Therefore, a tree that is currently 22 feet tall but is desired to be 10 feet tall is cut to about 18 feet in the first year, then cut to 14 feet in the second year, and then cut to the desired height (10 feet) in the third year. To avoid branch diseases, prune during early spring when dry weather is predicted for an extended period. This method assumes that there are three or four healthy and stable lateral limbs well below 10 feet, which is not always the case (fig.10). Cut limbs back to strong lateral branches where possible, although 

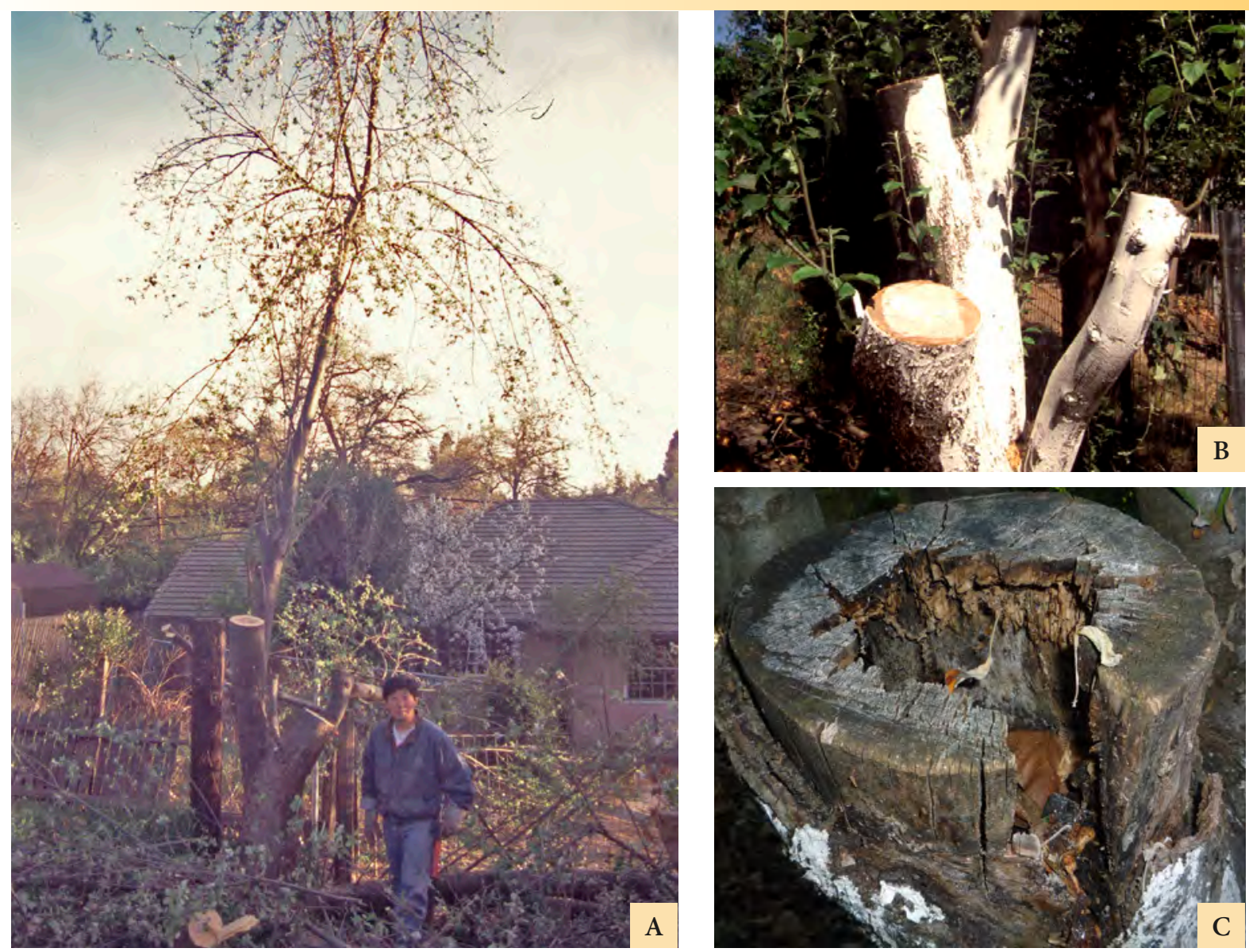

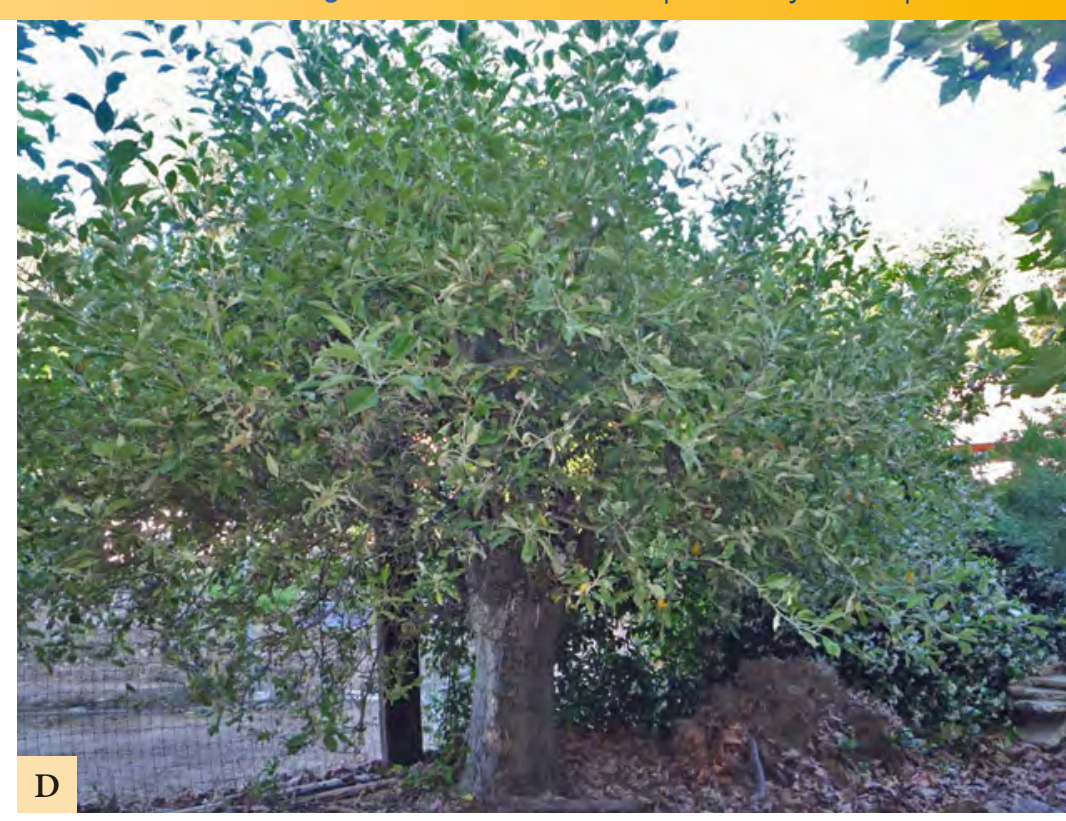

Figure 11. (A) This overgrown apple was severely headed in 1999 except for one temporary branch, which was removed the following year. (B) The branches were whitewashed. A small branch can be seen on the lower left limb, several inches below the cut. (C) By 2012, the cut limb was largely decayed because the lateral branch was too smal and too far below the cut to lead to wound closure. (D) However, 13 years after severe heading, the tree was still producing substantial fruit and the tree was manageable with only a small ladder. some heading cuts will likely be necessary. These cuts will stimulate vigorous shoot growth, so follow up by heavily thinning the new shoots in summer to allow sunlight to reach branches below the permanent height. If restorative pruning exposes limbs below the permanent height to several hours of late afternoon sun, paint the exposed surfaces of limbs on the north and east sides of the tree (i.e., surfaces facing south and west) with a 50-50 mixture of interior white latex paint and water to prevent sunburn. In the first year, strongly head back lateral branches low in the tree to generate new growth that can be developed into permanent low branches or fruiting wood (or both), and thin lower branches as needed.

A more radical approach is to reduce the height in just 1 year (fig. 11). The advantage with this method is that the tree can be reformed and brought back into production very quickly. However, this may be considered a temporary solution, since heading of fairly large branches may be necessary-and the cuts, depending on size, may result in wood rot. It is preferable to cut to lower laterals that are at least one-third the diameter of the stem. Decay is also more likely to develop if the resultant shoot growth is excessively thinned or not allowed to develop near the wound site. Sufficient leaf surface area of branches originating just below the large cuts is needed to produce callus growth to cover and close the wound. However, leaf area will likely be insufficient anyway if the tree is kept small. Another disadvantage is that shoot growth will be extremely vigorous and will need to be managed until fruit production is reestablished. The best timing for making the large cuts is March or April, after most winter rainfall and when shoot growth is beginning. Do not apply wound dressings to pruning wounds. 
Leave at least one temporary "nurse limb" of moderate size to provide food from photosynthesis for the roots. Exposed west- and south-facing branch surfaces should be whitewashed with a 50-50 mixture of interior white latex paint and water to prevent sunburn. Since the tree structure has already been determined, it may not be possible to create a tree with one of the specific training systems discussed above. Instead, work toward creating spaces for light to penetrate the canopy, directing growth outward, and heading back or removing vigorous shoots.

\section{References}

Ingels, C., P. Geisel, and M. Norton, eds. 2007. The home orchard: Growing your own deciduous fruit and nut trees. Oakland: University of California Agriculture and Natural Resources Publication 3485.

Ingels, C., P. Geisel, and C. Unruh. 2002. Fruit trees: Pruning overgrown deciduous trees. Oakland: University of California Agriculture and Natural Resources Publication 8058. Available at the UC ANR website, http://anrcatalog.ucanr.edu/ FruitNutTreesintheHomeGarden/8058.aspx.

UC Davis Fruit and Nut Research and Information website, http://fruitsandnuts.ucdavis.edu.

UC IPM Online website, www.ipm.ucdavis.edu.

\section{ACKNOWLEDGMENTS}

Special thanks to Bruce Hagen, editor of Western Arborist magazine, for his contribution to this publication. Western Arborist is produced by the Western Chapter of the International Society of Arboriculture.

\section{Measurement Conversion Table}

\begin{tabular}{|l|c|c|l|}
$\begin{array}{l}\text { U.S. } \\
\text { customary }\end{array}$ & $\begin{array}{c}\text { Conversion factor for } \\
\text { U.S. customary to metric }\end{array}$ & $\begin{array}{c}\text { Conversion factor } \\
\text { for metric to U.S. } \\
\text { customary }\end{array}$ & Metric \\
\hline inch (in) & 2.54 & 0.394 & centimeter (cm) \\
\hline foot (ft) & 0.3048 & 3.28 & meter (m) \\
\hline
\end{tabular}

\section{For More Information}

To order or obtain ANR publications and other products, visit the ANR Communication Services online catalog at http://anrcatalog.ucanr.edu or phone 1-800-994-8849. You can also place orders by mail or FAX, or request a printed catalog of our products from

University of California

Agriculture and Natural Resources

Communication Services

1301 S. 46th Street

Building 478 - MC 3580

Richmond, CA 94804-4600

Telephone 1-800-994-8849 510-665-2195 FAX 510-665-3427

E-mail: anrcatalog@ucanr.edu

(02014 The Regents of the University of California

Agriculture and Natural Resources

All rights reserved.

Publication 8502

ISBN-13: 978-1-60107-856-8

The University of California Division of Agriculture \& Natural Resources (ANR) prohibits discrimination against or harassment of any person participating in any of ANR's programs or activities on the basis of race, color, national origin, religion, sex, gender identity, pregnancy (which includes pregnancy, childbirth, and medical conditions related to pregnancy or childbirth), physical or mental disability, medical condition (cancer-related or genetic characteristics), genetic information (including family medical history), ancestry, marital status, age, sexual orientation, citizenship, or service in the uniformed services (as defined by the Uniformed Services Employment and Reemployment Rights Act of 1994: service in the uniformed services includes membership, application for membership, performance of service, application for service, or obligation for service in the uniformed services) or any person in any of its programs or activities.

University policy also prohibits retaliation against any employee or person participating in any of ANR's programs or activities for bringing a complaint of discrimination or harassment pursuant to this policy. This policy is intended to be consistent with the provisions of applicable State and Federal laws.

Inquiries regarding the University's equal employment opportunity policies may be directed to Linda Marie Manton, Affirmative Action Contact, University of California, Davis, Agriculture and Natural Resources, One Shields Avenue, Davis, CA 95616, 530-752-0495. For assistance in downloading this publication, telephone 530-750-1225.

To simplify information, trade names of products have been used. No endorsement of named or illustrated products is intended, nor is criticism implied of similar products that are not mentioned or illustrated.

An electronic copy of this publication can be found at the ANR Communication Services catalog website, http://anrcatalog.ucanr.edu/.

UC. This publication has been anonymously peer reviewed for technical accuracy by University Pelifornia scientists and other qualified professionals. This review process was managed by the ANR Associate Editor for Environmental Horticulture, Janet Hartin. 